\title{
VEGF-Independent Angiogenic Factors: Beyond VEGF/VEGFR2 Signaling
}

\author{
Ryoji Eguchi $^{a, b}$ Jun-ichi Kawabe ${ }^{b}$ Ichiro Wakabayashi ${ }^{a}$ \\ ${ }^{\text {aDDepartment }}$ Environmental and Preventive Medicine, Hyogo College of Medicine, Nishinomiya, Japan; \\ ${ }^{b}$ Department of Biochemistry, Asahikawa Medical University, Asahikawa, Japan
}

\section{Keywords}

Angiogenesis - Vascular endothelial growth factor - VEGF receptor $2 \cdot$ Bevacizumab $\cdot$ Ramucirumab

\begin{abstract}
Tumors induce angiogenesis to acquire oxygen and nutrition from their adjacent microenvironment. Tumor angiogenesis has been believed to be induced primarily by the secretion of vascular endothelial growth factor-A (VEGF-A) from various tumors. VEGF-A binds to VEGF receptor 2 (VEGFR2), resulting in subsequent activation of cellular substances regulating cell proliferation, survival, and angiogenesis. Antiangiogenic therapies targeting the VEGF-A/VEGFR2 axis, including bevacizumab and ramucirumab, humanized monoclonal antibodies against VEGF-A and VEGFR2, respectively, have been proposed as a promising strategy aimed at preventing tumor growth, invasion, and metastasis. Phase III clinical trials using bevacizumab and ramucirumab have shown that not all tumor patients benefit from such antiangiogenic agents, and that some patients who initially benefit subsequently become less responsive to these antibodies, suggesting the possible existence of VEGF-independent angiogenic factors. In this review, we focus on VEGF-independent and VEGFR2-dependent tumor angiogenesis, as well as VEGFR2-independent tumor angiogenesis. Additionally, we
\end{abstract}

karger@karger.com www.karger.com/jvr

(c) 2022 S. Karger AG, Basel

Karger" discuss VEGF-independent angiogenic factors which have been reported in previous studies. Various molecular targeting drugs are currently being evaluated as potential antitumor therapies. We expect that precision medicine will permit the development of innovative antiangiogenic therapies targeting individual angiogenic factors selected on the basis of the genetic screening of tumors.

(c) 2022 S. Karger AG, Basel

\section{Introduction}

Angiogenesis is defined, in a broad sense, as the formation of primary vascular networks by connection of vessels sprouting from primitive endothelium undergoing vasculogenesis; in this process, lumens are generated by aggregation of mesenchymal cells, including angioblasts, with subsequent growth toward existing neighbor vasculature [1]. Vasculogenesis and subsequent angiogenesis facilitate the growth of the primary network toward mature vasculatures, permitting the assembly of a circulatory system. Angiogenesis also occurs during the progression of tumor growth, by which tumors acquire oxygen and nutrition from their adjacent microenvironment to facilitate exponential tumor growth. These events lead to the remodeling of new vasculature from pre-existing 


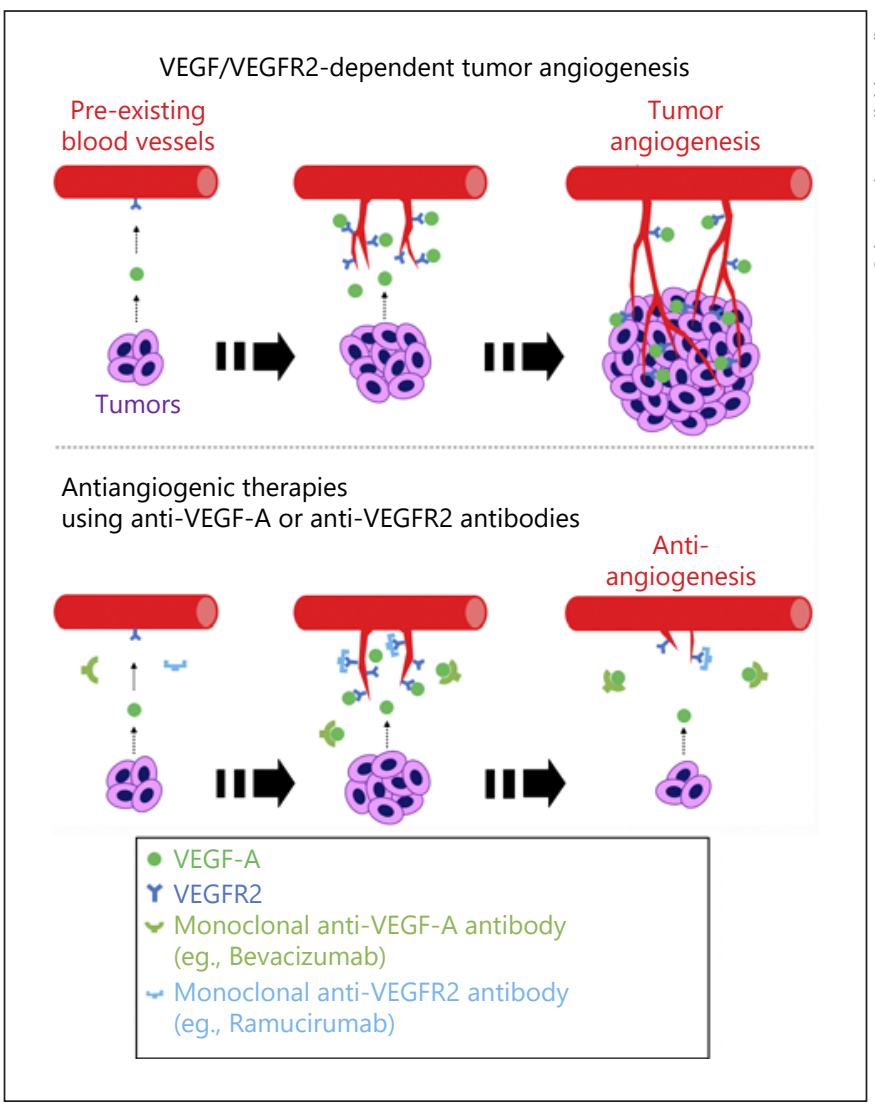

Fig. 1. VEGF/VEGFR2-dependent tumor angiogenesis and angiogenic therapies using anti-VEGF-A or anti-VEGFR2 antibodies. Tumor growth depends on the acquisition of oxygen and nutrition from the local microenvironment. To this end, tumors secrete VEGF-A toward pre-existing blood vessels. Sprouting from those vessels is mediated by binding of VEGF-A to VEGFR2, and the oxygen and nutrition supplied by the new vasculature enables tumor progression. Bevacizumab and ramucirumab bind to VEGF$A$ and VEGFR2, resulting in inhibition of this sprouting and antiangiogenic effects. VEGF-A, vascular endothelial growth factor-A; VEGFR2, VEGF receptor 2.

blood vessels, a process called neovascularization or tumor angiogenesis $[1,2]$.

Vasculogenesis or physiological and pathological angiogenesis is induced not only by growth factors but also by secretory proteins in paracrine and autocrine manners [1]. Among such angiogenic factors, vascular endothelial growth factor (VEGF, a member of the mammalian protein family that includes VEGF-A, -B, -C, and -D, as well as placenta growth factor), especially VEGF-A, is a major regulator of physiological and pathological angiogenesis as well as of vasculogenesis [3]. These VEGFs bind to VEGF receptors (VEGFRs, which include VEGFR-1-3) and neuropilins (neuropilin-1 and -2), resulting in autophosphorylation of the tyrosine residues in these receptors and subsequent activation of cellular substances, such as members of the mitogen-activated protein kinase (MAPK) superfamily and phosphatidylinositol 3-kinase (PI3K)/Akt, that regulate cell proliferation, differentiation, and survival [4]. The binding of VEGF-A to VEGFR2 is known to promote angiogenesis more strongly than other VEGF-VEGFR or -neuropilin signaling pairs [5].

Antiangiogenic therapies targeting the VEGF-A/ VEGFR2 axis, such as bevacizumab and ramucirumab, humanized monoclonal antibodies against VEGF-A and VEGFR2, respectively, have been proposed as promising strategies for the prevention of tumor growth, invasion, and metastasis [6] (Fig. 1). In phase III clinical trials, bevacizumab and ramucirumab have been used in combination with radiotherapy and various antitumor agents, including chemotherapeutic agents (Table 1). However, not all tumor patients benefit from such antiangiogenic antibodies; some patients who initially benefit from such agents subsequently become less responsive to such therapies and show various adverse effects. These observations suggest the possible existence of VEGF-independent angiogenic factors, but few reviews have focused on these factors. This review discusses VEGF/VEGFR2-independent tumor angiogenesis and factors associated with this process.

\section{The Possible Existence of VEGF-Independent and VEGFR2-Dependent Tumor Angiogenesis}

A previous clinical trial showed that the combination of folinic acid, 5-fluorouracil, and irinotecan (FOLFIRI) with bevacizumab is effective against metastatic colorectal cancer [7], which led to the investigation of bevacizumab as an antiangiogenic therapy (Table 1). Numerous phase III clinical trials also showed that bevacizumab significantly prolongs median progression-free survival (PFS) of patients with metastatic colorectal [7-10], breast [11-15], renal [16, 18], and prostate cancers [20], as well as non-small cell lung [21,22], pancreatic [24], gastric [25], ovarian [26, 28, 30-32], cervical [33], and small cell lung cancers [35], glioblastoma [36, 37], and malignant pleural mesothelioma [38]; however, the prolongation in these patients was a half year or less (Table 1). In contrast, median overall survival (OS) in these patients was not significantly prolonged by bevacizumab, except for some tumors such as metastatic colorectal cancer $[7,8,10]$, 







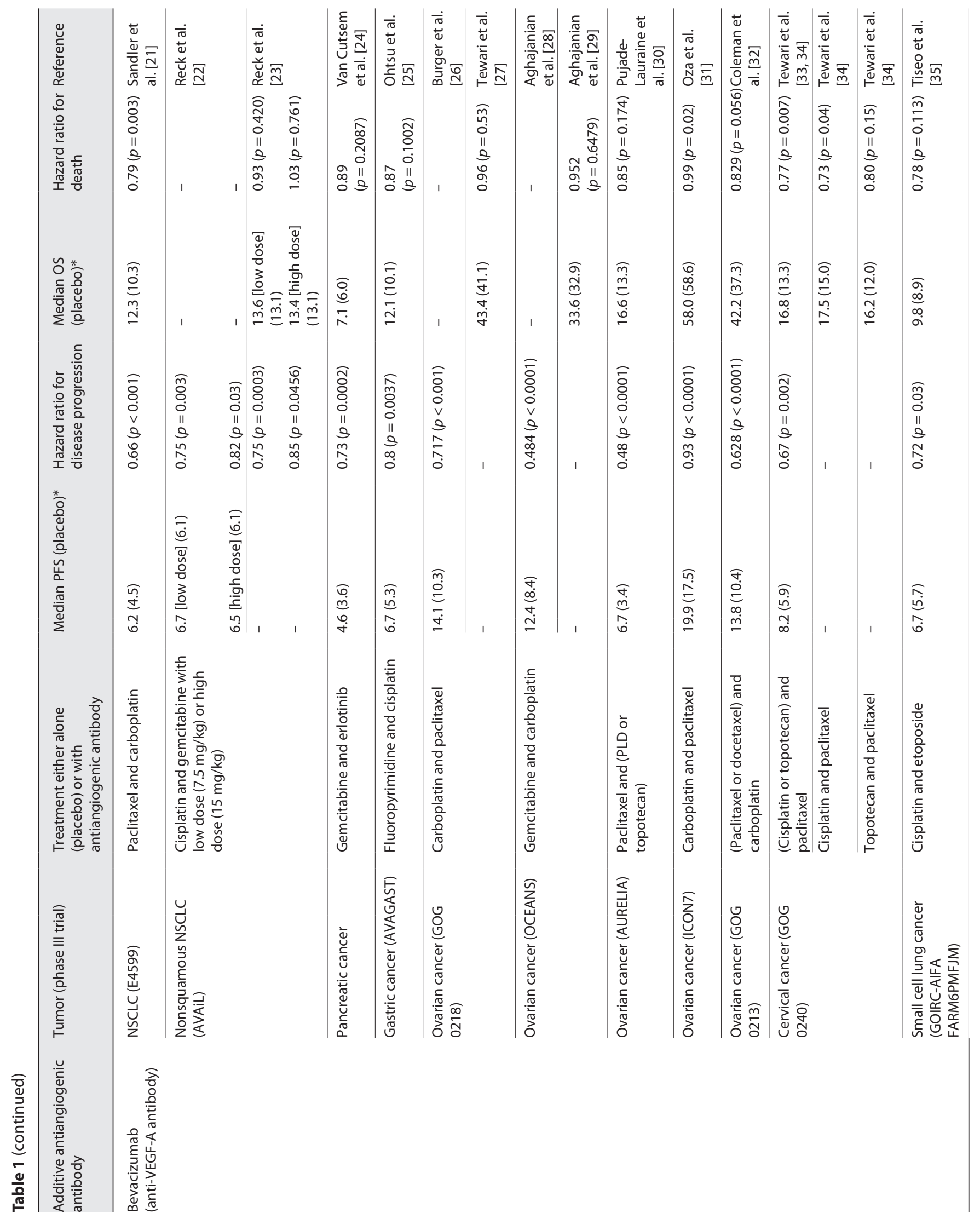




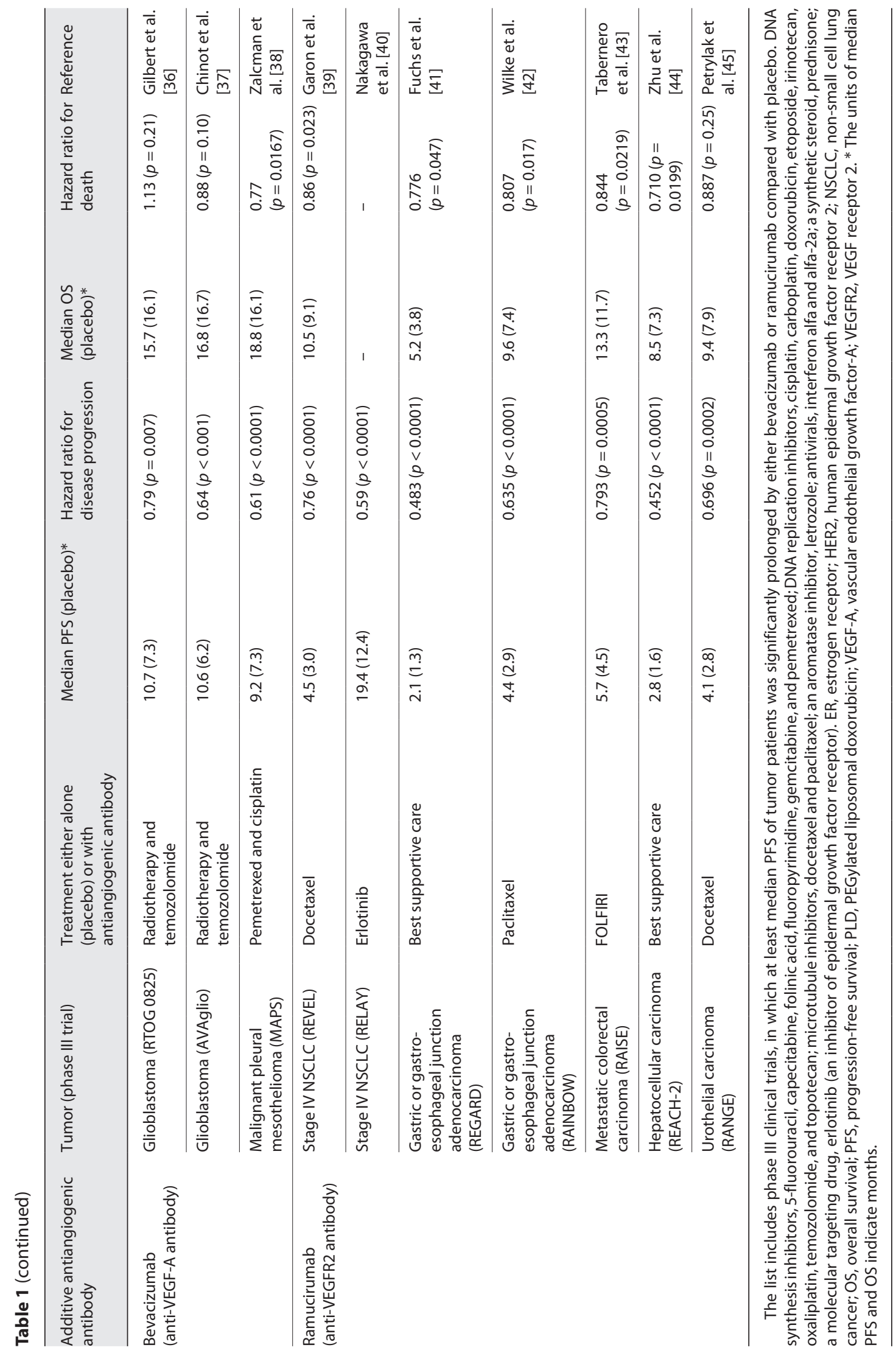


non-small cell lung [21] and cervical cancers [34], and malignant pleural mesothelioma [38]; in these trials, the prolongation of median OS of patients was less than 5 months. The results of these trials suggest that the antiVEGF antibody therapy suppresses tumor progression only temporarily, with re-initiation of tumor growth, occurring via a VEGF-independent angiogenic pathway.

Ramucirumab has been reported to improve median PFS of patients with various tumors such as stage IV nonsmall cell lung cancer (NSCLC) $[39,40]$, gastric or gastroesophageal junction adenocarcinoma [41, 42], metastatic colorectal cancer [43], and hepatocellular [44] and urothelial carcinomas [45]. Notably, to the best of our knowledge, no trials have directly compared the efficacy of bevacizumab to that of ramucirumab. Intriguingly, ramucirumab led to significant prolongation of the median OS in all patients, except those with urothelial carcinoma [45]; in contrast, bevacizumab was associated with nonsignificant prolongation of the median OS in patients with any of several tumors (Table 1). The results of these trials suggest the possible existence of VEGF-independent and VEGFR2-dependent tumor angiogenesis.

Secretory Angiogenic Factors That Induce VEGF Expression (VEGF-Dependent Angiogenesis) and

VEGF-Independent Angiogenesis (Including VEGFR2-

Dependent Angiogenesis)

Sphingosine-1 Phosphate

Sphingosine-1 phosphate (S1P), a bioactive sphingolipid derivative that regulates cell growth, survival, and angiogenesis [46], has been reported to be secreted from U87MG (a glioblastoma cell line) and primary diffuse large B-cell lymphoma, leading to tumor angiogenesis $[47,48]$. S1P binds to the S1P receptor, resulting in activation not only of MAPK and PI3K [46, 49] but also of VEGFR2, independently of VEGF, yielding MAPK- and PI3K-induced VEGF expression and VEGF-independent (though VEGFR2-dependent) angiogenesis $[46,50]$.

\section{Galectin-1}

Galectin-1, also known as $\beta$-galactoside-binding lectin protein, is a member of a glycan-binding protein family that regulates cell adhesion, differentiation, apoptosis, and angiogenesis [51]. Galectin-1 recognizes multiple galactose- $\beta 1-4-\mathrm{N}$-acetylglucosamine units, which are present on the branches of N- or O-linked glycans. VEGFR2 contains 18 putative N-linked glycosylation sites [52]. Croci et al. [52] revealed that galectin-1 derived from various anti-VEGF refractory tumors such as LLC1 (a Lewis lung cancer cell line) and R1.1 (a T-cell lympho-

VEGF-Independent Angiogenic Factors ma cell line) binds to the N-glycans on VEGFR2, which results in segregation of VEGFR2 to the cellular membrane and its internalization without VEGF in endothelial cells, leading to VEGF-independent (though VEGFR2-dependent) angiogenesis.

Sonic Hedgehog- or Signal Transducer and Activator of Transcription 3-Induced Cysteine-Rich

Angiogenic Inducer 61

Cysteine-rich angiogenic inducer 61 (CYR61), also known as cellular communication network factor 1 (CCN1), is a member of the CCN protein family, a group of proteins that regulate cell adhesion, proliferation, survival, and angiogenesis [53]. CYR61 is expressed and accumulates in early-stage breast tumor tissues [54]. Sonic hedgehog $(\mathrm{SHH})$, one of the $\mathrm{HH}$ proteins that play critical roles in development and homeostasis in various embryonic tissues [55], is also expressed in breast tumor tissues and activates the $\mathrm{HH}$ transcription factor Gli1 in an autocrine manner, resulting in upregulation of CYR61 expression and promotion of VEGF-independent angiogenesis [54]. In addition, Habel et al. [56] found that knockdown of CYR61 expression in osteosarcoma downregulates various angiogenic proteins, including VEGFA, leading to suppression of tumor angiogenesis. More recently, signal transducer and activator of transcription 3 (STAT3), a member of the STAT family that plays an important role in cell proliferation, differentiation, apoptosis, tumorigenesis, and angiogenesis [57], was detected in exosomes secreted from colorectal cancer cells; these exosomes have been shown to induce adipose-derived stem cells to upregulate CYR61 expression, yielding the formation by colorectal cancer cells of vasculaturemimicking tissue via a VEGF-independent process [58].

Lectin Galactoside-Binding Soluble 3 Binding

Protein

Elevated levels of lectin galactoside-binding soluble 3 binding protein (LGALS3BP) in serum or tumor tissue are known to be associated with shorter survival in patients with breast, non-small cell lung, and endometrial cancers, lymphoma, and malignant pleural mesothelioma $[59,60]$. Song et al. [60] recently found that LGALS3BP in plasma exosomes from patients with endometrial cancer induces tube formation and that exosomes containing LGALS3BP overexpressed in human embryonic kidney 293 cells upregulate VEGF expression, in human endothelial cell lines and primary endothelial cells. Similarly, Piccolo et al. [59] found that LGALS3BP secreted from MDA-MB-231, a human breast cancer cell line, upregu- 
lates VEGF expression in an autocrine manner, that knockdown of VEGF or LGALS3BP by RNA interference partially suppresses angiogenesis, and that knockdown of both completely inhibits angiogenesis. These studies suggest that LGALS3BP induces not only VEGF expression but also VEGF-independent angiogenesis directly and that the possible association of LGALS3BP with prognosis reflects tumor angiogenesis.

\section{Membrane-Type Angiogenic Inducers}

Fibulin-3-Induced Delta-Like Ligand 4 and Notch-1

Fibulin-3, also called epidermal growth factor-containing fibulin extracellular matrix protein 1 , is a secretory glycoprotein that is expressed widely in the human body, but is undetectable in normal brain tissue [61]. In addition, the binding of delta-like ligands (DLLs, DLL1, 3 , and 4) or Jagged 1 and 2 to their receptors, Notch proteins (Notch-1-4), is highly conserved, and DLL4/ Notch-1 signaling critically stimulates vascularization including tumor angiogenesis [62]. VEGF-A is also known to promote the expression of DLL4, but not that of Notch-1, in endothelial cells [63]. Nandhu et al. [64] found that overexpressed fibulin-3 induces not only the expression of VEGF and DLL4 in glioblastoma cells, but also that of Notch-1 and DLL4 in endothelial cells. These reports suggest a direct angiogenic stimulation by DLL4 on glioblastoma cells and by Notch-1 on endothelial cells, even if VEGF-A secreted by glioblastomas and VEGF-Amediated signaling are inhibited by bevacizumab or ramucirumab.

Erythropoietin-Producing Hepatoma Receptor B4

The binding of erythropoietin-producing hepatoma receptors (Ephs) to ephrin ligands, both of which exist in A- and B-types (EphA1 to A8 and A10, ephrin-A1 to A5, EphB1 to B4 and B6, and ephrin-B1 to B3), is known to result in signal transduction. The ephrin-B2/EphB4 axis is especially noted to play a pivotal role in angiogenesis [65]. Liu et al. [66] found that two malignant pleural mesothelioma cell lines (NCI-H2373 and MSTO-211H) overexpress EphB4, and that inhibition of EphB4 leads to suppression of tumor angiogenesis and progression. In addition, VEGF-A has previously been reported to suppress EphB4 expression in endothelial cells [65]. Together, these reports suggest that EphB4, if overexpressed in tumor tissues that do not also overproduce VEGF-A, may directly interact with ephrin-B2 in neighboring endothelial cells, leading to tumor angiogenesis, even if the VEGFA/VEGFR2 pathway is inhibited by bevacizumab or ramucirumab.
Desert Hedgehog and Patched 2

Azzi et al. [67] isolated cancer stem-like brain tumorinitiating cells (BTICs) derived from patients with glioblastoma. Notably, BTIC-derived conditioned medium induces tube formation, which was not completely suppressed by SU5416, a selective inhibitor of VEGFR2, in human endothelial cells. In addition, Azzi et al. [67] showed that the conditioned medium-induced and VEGFR2-independent tube formation is mediated by BTICexpressed desert hedgehog (DHH) and the DHH receptor Patched 2 (Ptch2) in a paracrine manner. DHH, like $\mathrm{SHH}$ (described above) [55], is a member of the $\mathrm{HH}$ protein family. Intriguingly, Azzi et al. [67] also found that a glioma cell line (U87) strongly expresses both $\mathrm{SHH}$, which induces the expression of both CYR61 (as described above) [54] and DHH, but BTICs express only DHH [67]. These studies suggest not only that differentiated tumors induce $\mathrm{SHH}$ expression with subsequent induction of CYR61 expression but also that cancer stemlike cells promote tumor angiogenesis via the induction of $\mathrm{DHH}$ production.

\section{Secretory VEGF- and VEGFR2-Independent}

Angiogenic Factors

Cyclooxygenase-2-Induced Prostaglandin $\mathrm{E}_{2}$

Cyclooxygenase-2 (COX-2, also known as prostaglandin-endoperoxide synthase 2) converts arachidonic acid to prostaglandin $\mathrm{H}_{2}\left(\mathrm{PGH}_{2}\right)$, a molecule that can in turn be converted enzymatically to any of the five major prostanoids. One of these products, $\mathrm{PGE}_{2}$, is the best-investigated prostanoid in the interaction between tumor progression and angiogenesis [68]. Xu et al. [69] showed that colorectal cancer cell line CT26-induced angiogenesis is not completely suppressed by DC101, an anti-VEGFR2 antibody, and axitinib, an inhibitor of multityrosine kinase including VEGFR2, and that these VEGFR2 inhibitors cannot suppress CT26 tumor growth at all. Furthermore, $\mathrm{Xu}$ et al. [69] revealed that overproduction of $\mathrm{PGE}_{2}$ by overexpressed COX-2 induces VEGF/VEGFR2-independent tumor angiogenesis in either of two colorectal cancer cell lines (CT26 and HCT116) and in a breast cancer cell line (4T1).

\section{Granulin}

Granulin (GRN), also called acrogranin and Paneth cell (PC)-derived growth factor, is secreted as a precursor protein progranulin (PGRN), cleaved by various extracellular proteases, and regulates wound healing, tumorigenesis, and angiogenesis [70]. Our findings demonstrated that serum-free culture supernatant derived from a ma- 
lignant pleural mesothelioma cell line (NCI-H2052; H2052 supernatant) induces tube formation in human endothelial cells, and that an anti-VEGF antibody and RNA interference for VEGFR2 cannot suppress H2052 supernatant-induced tube formation at all [71]. Furthermore, PGRN was identified in H2052 supernatant, in which PGRN and GRN-like protein induced VEGF-independent tube formation [71]. Overexpressed PGRN has been reported to upregulate VEGF-A expression and to induce angiogenesis in colorectal cancer cell lines [72]. In another work, Neill et al. [73] found that PGRN downregulates VEGF expression and induces angiogenesis in endothelial cells, a process that is mediated by the PGRN receptor, EphA2. The relationship between PGRN and VEGF-A remains controversial, but PGRN and its GRN derivative nonetheless have been shown to induce VEGFindependent angiogenesis.

Hepatoma-Derived Growth Factor

Hepatoma-derived growth factor (HDGF) is a secretory heparin-binding growth factor that is involved in tumorigenesis, metastasis, and angiogenesis [74]. We found that HDGF enhances VEGF-dependent angiogenesis in EBC-1, an NSCLC cell line [75]. HDGF has also been reported to upregulate VEGF expression in SK-HEP-1 (a hepatocellular carcinoma cell line) and SCC4 (an oral cancer cell line) $[76,77]$. These studies suggest that HDGF is involved not only in VEGF expression but also synergistically in VEGF-dependent angiogenesis.

\section{Fibroblast Growth Factor-2}

Fibroblast growth factor-2 (FGF-2), a member of the FGF protein family, is also referred to as basic FGF; this protein is a potent angiogenic factor with activity comparable to that of VEGF-A. FGF-2 is physiologically and pathologically a critical regulator of cell proliferation, survival, development, tumorigenesis, and angiogenesis [78]. As for HDGF, FGF-2 was shown to induce VEGFand HDGF-independent angiogenesis in Lu99, an NSCLC cell line that also expresses HDGF, as well as in the EBC1 cells described above [75]. In addition, Wang et al. [79] found that a humanized anti-FGF-2 antibody reduced tumor progression of NCI-H460, an NSCLC cell line, and microvascular density in vivo. These findings suggest that elevated FGF-2 expression may be a cause of VEGF-independent tumor angiogenesis. Go et al. [80] also reported that consequential suppression of FGF-2 by peginterferon $a-2 b$ was associated with clinical response or stable disease in patients with stage IV metastatic melanoma overexpressing FGF-2.

VEGF-Independent Angiogenic Factors

\section{A Secretory Nonprotein Angiogenic Inducer}

Dickkopf-Related Protein 2-Induced Lactate

Dickkopf-related protein 2 (DKK2), a member of the dickkopf family (which includes DKK1 to 4 and dickkopf-like protein 1, DKKL1), has been shown to bind to lipoprotein receptor-related protein-5 and -6 , type I transmembrane proteins [81], resulting in modulation of the activity of the $\mathrm{Wnt} / \beta$-catenin axis, an evolutionarily conserved signaling pathway involved in embryonic development, cell proliferation and differentiation, adult stem cell homeostasis, and regeneration [82]. Intriguingly, Deng et al. [83] found that secreted DKK2 binds to lipoprotein receptor-related protein 6 in an autocrine manner and promotes glycolysis with subsequent secretion of lactate in metastatic colorectal cancer, and they clarified that the secreted lactate is taken up via monocarboxylate transporter in endothelial cells, leading to tumor angiogenesis. This observation indicates the indirect involvement of a secretory nonprotein angiogenic inducer in tumor angiogenesis.

\section{Tumor/Cancer-Derived Extracellular Vesicles as}

\section{Mediators of Angiogenic Induction}

Tumor-Derived Exosomes Containing Tetraspanin 8

Extracellular vesicles (EVs), including exosomes, are vesicles $50-100 \mathrm{~nm}$ in diameter that are derived from endosome-forming multivesicular bodies generated from many types of cells upon activation by various environmental stresses and diseases, including cancer [84]. Notably, EVs are highly enriched in tetraspanins, members of a protein superfamily that have been shown to organize membrane microdomains (termed tetraspaninenriched microdomains) by forming clusters and interacting with a large variety of transmembrane and cytosolic signaling proteins [85]. Nazarenko et al. [86] found that pancreatic adenocarcinoma-derived exosomes containing one such tetraspanin, Tspan8, bind to endothelial cells and induce tumor angiogenesis. This observation suggests that angiogenic signaling by tumor-derived exosomes does not require endocytosis of the EVs by endothelial cells; binding of EVs to endothelial cells may suffice.

VEGF $_{189}$ on the Surface of Cancer-Derived Small Extracellular Vesicle (sEV-Associated VEGF ${ }_{189}$ )

Ko et al. [87] revealed that sEV-VEGF-induced angiogenesis in various cancer cell lines, including ES2 (ovarian), HCT116 (colon), and 786-0 (renal), and primary cells derived from patients with ovarian cancer are mediated by VEGFR2, but not by uptake of sEV, in endothe- 


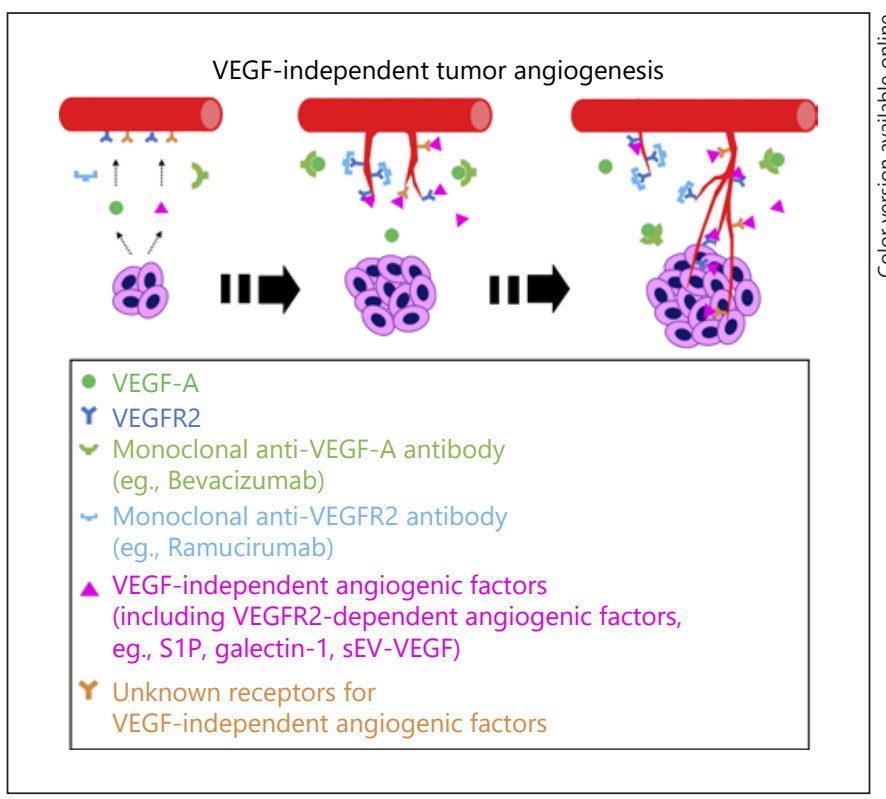

Fig. 2. VEGF-independent tumor angiogenesis. Bevacizumab inhibits binding of VEGF-A to VEGFR2, but not VEGFR2-dependent angiogenesis induced by S1P, galectin-1, and sEV-VEGF. Ramucirumab inhibits both VEGF- and VEGFR2-dependent angiogenesis, but not VEGF/VEGFR2-independent angiogenesis. Secretory and membrane-type VEGF-independent angiogenic factors bind to their receptors, resulting in induction of VEGF/ VEGFR2-independent tumor angiogenesis. VEGF-A, vascular endothelial growth factor-A; VEGFR2, VEGF receptor 2; S1P, sphingosine-1 phosphate; sEV-VEGF, sEV-associated $\mathrm{VEGF}_{189}$ (VEGF $_{189}$ on the surface of cancer-derived small extracellular vesicle).

lial cells. This finding suggests that inhibition of sEV uptake by endocytosis inhibitors does not suppress sEV-induced angiogenesis mediated by VEGFR2.

\section{Conclusion}

Numerous phase III clinical trials using bevacizumab and ramucirumab have suggested the possible existence of VEGF-independent and VEGFR2-dependent tumor angiogenesis (Fig. 2). In fact, S1P, galectin-1, and sEVVEGF can be regarded as VEGF-independent and VEGFR2-dependent angiogenic factors. Plasma-membrane ligands and their receptors, including DLL4/Notch-1 and ephrin-B2/EphB4, can also be targeted to both tumors and endothelial cells, or between endothelial cells, as novel anti-VEGF/VEGFR2-independent angiogenic therapies. However, our understanding of VEGF/VEGFR2- and angiogenic ligand/receptor-independent tumor angiogenesis remains a challenge (Fig. 2). This review discussed various VEGF-independent angiogenic factors or inducers (including CYR61, LGALS3BP, DHH/Ptch2, $\mathrm{PGE}_{2}$, GRN, HDGF, FGF-2, lactate, and exosomes containing Tspan8) mediating tumor angiogenesis by processes that are not VEGFR2- or angiogenic ligand/receptor-dependent.

With the exception of secretory or membranous ligand-linked angiogenic factors derived from tumors, there are at least two possibilities in VEGF/VEGFR2-independent tumor angiogenesis: (1) the involvement of angiogenic factors derived from tumor microenvironments, including cancer-associated fibroblasts and tumor-associated macrophages, and (2) vascular mimicry by dedifferentiation of tumor/cancer cells and by transdifferentiation of tumor/cancer stem cells. In this review, we focused solely on VEGF-independent angiogenic factors derived directly from tumor/cancer cells in terms of prolongation of median OS, as well as median PFS, by ramucirumab (Table 1), which may lead to inhibition of VEGF-independent and VEGFR2-dependent angiogenesis induced by S1P, galectin-1, or sEV-VEGF. These possibilities need to be explored in greater detail in another review.

Various molecular targeting drugs are currently selected as antitumor therapies based on the results of genepanel screens, in which expressions of oncogenes, tumor suppressor genes, and kinases with dominant active mutation, that are persistently activated by mutation of enzymatic active sites, can be determined to be upregulated or downregulated. In the future, we hope that more clinical trials will be performed comparing the efficacy of ramucirumab to that of bevacizumab. Additionally, we expect that precision medicine will facilitate the development of innovative antiangiogenic therapies targeted to individual angiogenic factors selected on the basis of genetic screening of tumors.

\section{Statement of Ethics}

This review manuscript contains no original data arising from animal or human studies.

\section{Conflict of Interest Statement}

The authors have no conflicts of interest to declare.
Eguchi/Kawabe/Wakabayashi 


\section{Funding Sources}

Not applicable.

\section{Author Contributions}

R.E. drafted the manuscript, created Figures 1, 2 and Table 1, and edited the manuscript. I.W. and J.K. reviewed the manuscript and made important intellectual contributions. R.E., J.K., and I.W. approved the final version of the manuscript.

\section{References}

1 Welti J, Loges S, Dimmeler S, Carmeliet P. Recent molecular discoveries in angiogenesis and antiangiogenic therapies in cancer. J Clin Invest. 2013 Aug;123(8):3190-200.

2 Hanahan D, Folkman J. Patterns and emerging mechanisms of the angiogenic switch during tumorigenesis. Cell. 1996 Aug;86(3):35364.

3 Dvorak HF. Vascular permeability factor/vascular endothelial growth factor: a critical cytokine in tumor angiogenesis and a potential target for diagnosis and therapy. J Clin Oncol. 2002 Nov;20(21):4368-80.

4 Kerbel RS. Tumor angiogenesis. N Engl J Med. 2008 May;358(19):2039-49.

5 Ferrara N. Vascular endothelial growth factor: basic science and clinical progress. Endocr Rev. 2004 Aug;25(4):581-611.

6 Ebos JM, Kerbel RS. Antiangiogenic therapy: impact on invasion, disease progression, and metastasis. Nat Rev Clin Oncol. 2011 Mar; $8(4): 210-21$.

7 Hurwitz H, Fehrenbacher L, Novotny W, Cartwright T, Hainsworth J, Heim W, et al. Bevacizumab plus irinotecan, fluorouracil, and leucovorin for metastatic colorectal cancer. N Engl J Med. 2004 Jun;350(23):2335-42.

8 Giantonio BJ, Catalano PJ, Meropol NJ, O’Dwyer PJ, Mitchell EP, Alberts SR, et al. Bevacizumab in combination with oxaliplatin, fluorouracil, and leucovorin (FOLFOX4) for previously treated metastatic colorectal cancer: results from the Eastern Cooperative Oncology Group Study E3200. J Clin Oncol. 2007 Apr;25(12):1539-44.

9 Saltz LB, Clarke S, Díaz-Rubio E, Scheithauer W, Figer A, Wong R, et al. Bevacizumab in combination with oxaliplatin-based chemotherapy as first-line therapy in metastatic colorectal cancer: a randomized phase III study. J Clin Oncol. 2008 Apr;26(12):2013-9.

10 Cremolini C, Loupakis F, Masi G, Lonardi S, Granetto C, Mancini ML, et al. FOLFOXIRI or FOLFOXIRI plus bevacizumab as first-line treatment of metastatic colorectal cancer: a propensity score-adjusted analysis from two randomized clinical trials. Ann Oncol. 2016 May;27(5):843-9.

11 Miller K, Wang M, Gralow J, Dickler M, Cobleigh M, Perez EA, et al. Paclitaxel plus bevacizumab versus paclitaxel alone for metastatic breast cancer. N Engl J Med. 2007 Dec; 357(26):2666-76.
12 Miles DW, Chan A, Dirix LY, Cortés J, Pivot $\mathrm{X}$, Tomczak P, et al. Phase III study of bevacizumab plus docetaxel compared with placebo plus docetaxel for the first-line treatment of human epidermal growth factor receptor 2-negative metastatic breast cancer. J Clin Oncol. 2010 Jul;28(20):3239-47.

13 Dickler MN, Barry WT, Cirrincione CT, Ellis MJ, Moynahan ME, Innocenti F, et al. Phase III trial evaluating letrozole as first-line endocrine therapy with or without bevacizumab for the treatment of postmenopausal women with hormone receptor-positive advancedstage breast cancer: CALGB 40503 (alliance). J Clin Oncol. 2016 Aug;34(22):2602-9.

14 Miles D, Cameron D, Bondarenko I, Manzyuk L, Alcedo JC, Lopez RI, et al. Bevacizumab plus paclitaxel versus placebo plus paclitaxel as first-line therapy for HER2-negative metastatic breast cancer (MERiDiAN): a double-blind placebo-controlled randomised phase III trial with prospective biomarker evaluation. Eur J Cancer. 2017 Jan;70:146-55.

15 Miles D, Cameron D, Hilton M, Garcia J, O'Shaughnessy J. Overall survival in MERiDiAN, a double-blind placebo-controlled randomised phase III trial evaluating first-line bevacizumab plus paclitaxel for HER2-negative metastatic breast cancer. Eur J Cancer. 2018 Feb;90:153-5.

16 Escudier B, Pluzanska A, Koralewski P, Ravaud A, Bracarda S, Szczylik C, et al. Bevacizumab plus interferon alfa-2a for treatment of metastatic renal cell carcinoma: a randomised, double-blind phase III trial. Lancet. 2007 Dec; 370(9605):2103-11.

17 Escudier B, Bellmunt J, Négrier S, Bajetta E, Melichar B, Bracarda S, et al. Phase III trial of bevacizumab plus interferon alfa-2a in patients with metastatic renal cell carcinoma (AVOREN): final analysis of overall survival. J Clin Oncol. 2010 May;28(13):2144-50.

18 Rini BI, Halabi S, Rosenberg JE, Stadler WM, Vaena DA, Ou SS, et al. Bevacizumab plus interferon alfa compared with interferon alfa monotherapy in patients with metastatic renal cell carcinoma: CALGB 90206. J Clin Oncol. 2008 Nov;26(33):5422-8.

19 Rini BI, Halabi S, Rosenberg JE, Stadler WM, Vaena DA, Archer L, et al. Phase III trial of bevacizumab plus interferon alfa versus interferon alfa monotherapy in patients with metastatic renal cell carcinoma: final results of CALGB 90206. J Clin Oncol. 2010 May; 28(13):2137-43.
20 Kelly WK, Halabi S, Carducci M, George D, Mahoney JF, Stadler WM, et al. Randomized, double-blind, placebo-controlled phase III trial comparing docetaxel and prednisone with or without bevacizumab in men with metastatic castration-resistant prostate cancer: CALGB 90401. J Clin Oncol. 2012 May; 30(13):1534-40.

21 Sandler A, Gray R, Perry MC, Brahmer J, Schiller JH, Dowlati A, et al. Paclitaxel-carboplatin alone or with bevacizumab for nonsmall-cell lung cancer. N Engl J Med. 2006 Dec;355(24):2542-50.

22 Reck M, von Pawel J, Zatloukal P, Ramlau R, Gorbounova V, Hirsh V, et al. Phase III trial of cisplatin plus gemcitabine with either placebo or bevacizumab as first-line therapy for nonsquamous non-small-cell lung cancer: AVAil. J Clin Oncol. 2009 Mar;27(8):122734.

23 Reck M, von Pawel J, Zatloukal P, Ramlau R, Gorbounova V, Hirsh V, et al. Overall survival with cisplatin-gemcitabine and bevacizumab or placebo as first-line therapy for nonsquamous non-small-cell lung cancer: results from a randomised phase III trial (AVAiL). Ann Oncol. 2010 Sep;21(9):1804-9.

24 Van Cutsem E, Vervenne WL, Bennouna J, Humblet Y, Gill S, Van Laethem JL, et al. Phase III trial of bevacizumab in combination with gemcitabine and erlotinib in patients with metastatic pancreatic cancer. J Clin Oncol. 2009 May;27(13):2231-7.

25 Ohtsu A, Shah MA, Van Cutsem E, Rha SY, Sawaki A, Park SR, et al. Bevacizumab in combination with chemotherapy as first-line therapy in advanced gastric cancer: a randomized, double-blind, placebo-controlled phase III study. J Clin Oncol. 2011 Oct;29(30):396876.

26 Burger RA, Brady MF, Bookman MA, Fleming GF, Monk BJ, Huang $\mathrm{H}$, et al. Incorporation of bevacizumab in the primary treatment of ovarian cancer. N Engl J Med. 2011 Dec; 365(26):2473-83.

27 Tewari KS, Burger RA, Enserro D, Norquist BM, Swisher EM, Brady MF, et al. Final overall survival of a randomized trial of bevacizumab for primary treatment of ovarian cancer. J Clin Oncol. 2019 Sep;37(26):2317-28. 
28 Aghajanian C, Blank SV, Goff BA, Judson PL, Teneriello MG, Husain A, et al. OCEANS: a randomized, double-blind, placebo-controlled phase III trial of chemotherapy with or without bevacizumab in patients with platinum-sensitive recurrent epithelial ovarian, primary peritoneal, or fallopian tube cancer. J Clin Oncol. 2012 Jun;30(17):2039-45.

29 Aghajanian C, Goff B, Nycum LR, Wang YV, Husain A, Blank SV. Final overall survival and safety analysis of OCEANS, a phase 3 trial of chemotherapy with or without bevacizumab in patients with platinum-sensitive recurrent ovarian cancer. Gynecol Oncol. 2015 Oct; 139(1):10-6.

30 Pujade-Lauraine E, Hilpert F, Weber B, Reuss A, Poveda A, Kristensen G, et al. Bevacizumab combined with chemotherapy for platinumresistant recurrent ovarian cancer: the AURELIA open-label randomized phase III trial. J Clin Oncol. 2014 May;32(13):1302-8.

31 Oza AM, Cook AD, Pfisterer J, Embleton A, Ledermann JA, Pujade-Lauraine E, et al. Standard chemotherapy with or without bevacizumab for women with newly diagnosed ovarian cancer (ICON7): overall survival results of a phase 3 randomised trial. Lancet Oncol. 2015 Aug; 16(8):928-36.

32 Coleman RL, Brady MF, Herzog TJ, Sabbatini $\mathrm{P}$, Armstrong DK, Walker JL, et al. Bevacizumab and paclitaxel-carboplatin chemotherapy and secondary cytoreduction in recurrent, platinum-sensitive ovarian cancer (NRG Oncology/Gynecologic Oncology Group study GOG-0213): a multicentre, open-label, randomised, phase 3 trial. Lancet Oncol. 2017 Jun;18(6):779-91.

33 Tewari KS, Sill MW, Long HJ 3rd, Penson RT, Huang H, Ramondetta LM, et al. Improved survival with bevacizumab in advanced cervical cancer. N Engl J Med. 2014 Feb;370(8) $734-43$.

34 Tewari KS, Sill MW, Penson RT, Huang H, Ramondetta LM, Landrum LM, et al. Bevacizumab for advanced cervical cancer: final overall survival and adverse event analysis of a randomised, controlled, open-label, phase 3 trial (Gynecologic Oncology Group 240) Lancet. 2017 Oct;390(10103):1654-63.

35 Tiseo M, Boni L, Ambrosio F, Camerini A, Baldini E, Cinieri S, et al. Italian, multicenter, phase III, randomized study of cisplatin plus etoposide with or without bevacizumab as first-line treatment in extensive-disease small-cell lung cancer: the GOIRC-AIFA FARM6PMFJM trial. J Clin Oncol. 2017 Apr; 35(12):1281-7.

36 Gilbert MR, Dignam JJ, Armstrong TS, Wefel JS, Blumenthal DT, Vogelbaum MA, et al. A randomized trial of bevacizumab for newly diagnosed glioblastoma. N Engl J Med. 2014 Feb;370(8):699-708.

37 Chinot OL, Wick W, Mason W, Henriksson R, Saran F, Nishikawa R, et al. Bevacizumab plus radiotherapy-temozolomide for newly diagnosed glioblastoma. N Engl J Med. 2014 Feb;370(8):709-22.
38 Zalcman G, Mazieres J, Margery J, Greillier L, Audigier-Valette C, Moro-Sibilot D, et al. Bevacizumab for newly diagnosed pleural mesothelioma in the Mesothelioma Avastin Cisplatin Pemetrexed Study (MAPS): a randomised, controlled, open-label, phase 3 trial. Lancet. 2016 Apr;387(10026):1405-14.

39 Garon EB, Ciuleanu TE, Arrieta O, Prabhash $\mathrm{K}$, Syrigos KN, Goksel T, et al. Ramucirumab plus docetaxel versus placebo plus docetaxel for second-line treatment of stage IV nonsmall-cell lung cancer after disease progression on platinum-based therapy (REVEL): a multicentre, double-blind, randomised phase 3 trial. Lancet. 2014 Aug;384(9944):665-73.

40 Nakagawa K, Garon EB, Seto T, Nishio M, Ponce Aix S, Paz-Ares L, et al. Ramucirumab plus erlotinib in patients with untreated, EGFR-mutated, advanced non-small-cell lung cancer (RELAY): a randomised, doubleblind, placebo-controlled, phase 3 trial. Lancet Oncol. 2019 Dec;20(12):1655-69.

41 Fuchs CS, Tomasek J, Yong CJ, Dumitru F, Passalacqua R, Goswami C, et al. Ramucirumab monotherapy for previously treated advanced gastric or gastro-oesophageal junction adenocarcinoma (REGARD): an international, randomised, multicentre, placebo-controlled, phase 3 trial. Lancet. 2014 Jan; 383(9911):31-9.

42 Wilke H, Muro K, Van Cutsem E, Oh SC, Bodoky G, Shimada Y, et al. Ramucirumab plus paclitaxel versus placebo plus paclitaxel in patients with previously treated advanced gastric or gastro-oesophageal junction adenocarcinoma (RAINBOW): a double-blind, randomised phase 3 trial. Lancet Oncol. 2014 Oct;15(11):1224-35.

43 Tabernero J, Yoshino T, Cohn AL, Obermannova R, Bodoky G, Garcia-Carbonero R, et al. Ramucirumab versus placebo in combination with second-line FOLFIRI in patients with metastatic colorectal carcinoma that progressed during or after first-line therapy with bevacizumab, oxaliplatin, and a fluoropyrimidine (RAISE): a randomised, double-blind, multicentre, phase 3 study. Lancet Oncol. 2015 May; 16(5):499-508.

44 Zhu AX, Kang YK, Yen CJ, Finn RS, Galle PR, Llovet JM, et al. Ramucirumab after sorafenib in patients with advanced hepatocellular carcinoma and increased $\alpha$-fetoprotein concentrations (REACH-2): a randomised, doubleblind, placebo-controlled, phase 3 trial. Lancet Oncol. 2019 Feb;20(2):282-96.

45 Petrylak DP, de Wit R, Chi KN, Drakaki A, Sternberg CN, Nishiyama H, et al. Ramucirumab plus docetaxel versus placebo plus docetaxel in patients with locally advanced or metastatic urothelial carcinoma after platinum-based therapy (RANGE): overall survival and updated results of a randomised, double-blind, phase 3 trial. Lancet Oncol. 2020 Jan;21(1):105-20.

46 Hisano Y, Hla T. Bioactive lysolipids in cancer and angiogenesis. Pharmacol Ther. 2019 Jan; 193:91-8.
47 Abuhusain HJ, Matin A, Qiao Q, Shen H, Kain N, Day BW, et al. A metabolic shift favoring sphingosine 1-phosphate at the expense of ceramide controls glioblastoma angiogenesis. J Biol Chem. 2013 Dec;288(52): 37355-64.

48 Lupino L, Perry T, Margielewska S, Hollows R, Ibrahim M, Care M, et al. Sphingosine1-phosphate signalling drives an angiogenic transcriptional programme in diffuse large $B$ cell lymphoma. Leukemia. 2019 Dec;33(12): 2884-97.

49 Graupera M, Potente M. Regulation of angiogenesis by PI3K signaling networks. Exp Cell Res. 2013 May;319(9):1348-55.

50 Heo K, Park KA, Kim YH, Kim SH, Oh YS, $\mathrm{Kim} \mathrm{IH}$, et al. Sphingosine 1-phosphate induces vascular endothelial growth factor expression in endothelial cells. BMB Rep. 2009 Oct;42(10):685-90.

51 Thijssen VL, Griffioen AW. Galectin-1 and -9 in angiogenesis: a sweet couple. Glycobiology. 2014 Oct;24(10):915-20.

52 Croci DO, Cerliani JP, Dalotto-Moreno T, Méndez-Huergo SP, Mascanfroni ID, Dergan-Dylon S, et al. Glycosylation-dependent lectin-receptor interactions preserve angiogenesis in anti-VEGF refractory tumors. Cell. 2014 Feb;156(4):744-58.

53 Lau LF. CCN1/CYR61: the very model of a modern matricellular protein. Cell Mol Life Sci. 2011 Oct;68(19):3149-63.

54 Harris LG, Pannell LK, Singh S, Samant RS, Shevde LA. Increased vascularity and spontaneous metastasis of breast cancer by hedgehog signaling mediated upregulation of cyr61. Oncogene. 2012 Jul;31(28):3370-80.

55 Sasai N, Toriyama M, Kondo T. Hedgehog signal and genetic disorders. Front Genet. 2019;10:1103.

56 Habel N, Vilalta M, Bawa O, Opolon P, Blanco J, Fromigué O. Cyr61 silencing reduces vascularization and dissemination of osteosarcoma tumors. Oncogene. 2015 Jun;34(24): 3207-13.

57 Chen Z, Han ZC. STAT3: a critical transcription activator in angiogenesis. Med Res Rev. 2008 Mar;28(2):185-200.

58 Liang Z, Liu H, Zhang Y, Xiong L, Zeng Z, He $\mathrm{X}$, et al. Cyr61 from adipose-derived stem cells promotes colorectal cancer metastasis and vasculogenic mimicry formation via integrin $\alpha(V) \beta(5)$. Mol Oncol. 2021 May; 15(12): 3447-67.

59 Piccolo E, Tinari N, Semeraro D, Traini S, Fichera I, Cumashi A, et al. LGALS3BP, lectin galactoside-binding soluble 3 binding protein, induces vascular endothelial growth factor in human breast cancer cells and promotes angiogenesis. J Mol Med. 2013 Jan;91(1):8394.

60 Song $\mathrm{Y}$, Wang $\mathrm{M}$, Tong $\mathrm{H}$, Tan $\mathrm{Y}, \mathrm{Hu} \mathrm{X}$, Wang K, et al. Plasma exosomes from endometrial cancer patients contain LGALS3BP to promote endometrial cancer progression. Oncogene. 2021 Jan;40(3):633-46. 
61 Livingstone I, Uversky VN, Furniss D, Wiberg A. The pathophysiological significance of fibulin-3. Biomolecules. 2020 Sep; 10(9): 1294.

62 Akil A, Gutiérrez-García AK, Guenter R, Rose JB, Beck AW, Chen $\mathrm{H}$, et al. Notch signaling in vascular endothelial cells, angiogenesis, and tumor progression: an update and prospective. Front Cell Dev Biol. 2021;9:642352.

63 Yang C, Guo Y, Jadlowiec CC, Li X, Lv W, Model LS, et al. Vascular endothelial growth factor-A inhibits EphB4 and stimulates deltalike ligand 4 expression in adult endothelial cells. J Surg Res. 2013 Jul;183(1):478-86.

64 Nandhu MS, Hu B, Cole SE, Erdreich-Epstein A, Rodriguez-Gil DJ, Viapiano MS. Novel paracrine modulation of Notch-DLL4 signaling by fibulin-3 promotes angiogenesis in high-grade gliomas. Cancer Res. 2014 Oct; 74(19):5435-48.

65 Du E, Li X, He S, Li X, He S. The critical role of the interplays of EphrinB2/EphB4 and VEGF in the induction of angiogenesis. Mol Biol Rep. 2020 Jun;47(6):4681-90.

66 Liu R, Ferguson BD, Zhou Y, Naga K, Salgia $\mathrm{R}$, Gill PS, et al. EphB4 as a therapeutic target in mesothelioma. BMC cancer. 2013 May; 13: 269.

67 Azzi S, Treps L, Leclair HM, Ngo HM, Harford-Wright E, Gavard J. Desert hedgehog/ patch2 axis contributes to vascular permeability and angiogenesis in glioblastoma. Front Pharmacol. 2015;6:281.

68 Salvado MD, Alfranca A, Haeggström JZ, Redondo JM. Prostanoids in tumor angiogenesis: therapeutic intervention beyond COX-2. Trends Mol Med. 2012 Apr;18(4):233-43.

$69 \mathrm{Xu}$ L, Stevens J, Hilton MB, Seaman S, Conrads TP, Veenstra TD, et al. COX-2 inhibition potentiates antiangiogenic cancer therapy and prevents metastasis in preclinical models. Sci Transl Med. 2014 Jun;6(242):242ra84.
$70 \mathrm{He}$ Z, Bateman A. Progranulin (granulin-epithelin precursor, PC-cell-derived growth factor, acrogranin) mediates tissue repair and tumorigenesis. J Mol Med. 2003 Oct;81(10): 600-12.

71 Eguchi R, Nakano T, Wakabayashi I. Progranulin and granulin-like protein as novel VEGF-independent angiogenic factors derived from human mesothelioma cells. Oncogene. 2017 Feb;36(5):714-22.

72 Yang D, Wang LL, Dong TT, Shen YH, Guo XS, Liu CY, et al. Progranulin promotes colorectal cancer proliferation and angiogenesis through TNFR2/Akt and ERK signaling pathways. Am J Cancer Res. 2015;5(10): 3085-97.

73 Neill T, Buraschi S, Goyal A, Sharpe C, Natkanski E, Schaefer L, et al. EphA2 is a functional receptor for the growth factor progranulin. J Cell Biol. 2016 Dec;215(5):687-703.

74 Bao C, Wang J, Ma W, Wang X, Cheng Y. HDGF: a novel jack-of-all-trades in cancer. Future Oncol. 2014 Dec;10(16):2675-85.

75 Eguchi R, Wakabayashi I. HDGF enhances VEGFdependent angiogenesis and FGF2 is a VEGFindependent angiogenic factor in nonsmall cell lung cancer. Oncol Rep. 2020 Jul; 44(1):14-28.

76 Enomoto H, Nakamura H, Liu W, Iwata Y, Nishikawa H, Takata R, et al. Down-regulation of HDGF inhibits the growth of hepatocellular carcinoma cells in vitro and in vivo. Anticancer Res. 2015 Dec;35(12):6475-9.

77 Lin YW, Huang ST, Wu JC, Chu TH, Huang SC, Lee CC, et al. Novel HDGF/HIF-1a/ VEGF axis in oral cancer impacts disease prognosis. BMC cancer. 2019 Nov; 19(1): 1083 .

78 Akl MR, Nagpal P, Ayoub NM, Tai B, Prabhu SA, Capac CM, et al. Molecular and clinical significance of fibroblast growth factor 2 (FGF2 /bFGF) in malignancies of solid and hematological cancers for personalized therapies. Oncotarget. 2016 Jul;7(28):44735-62.
79 Wang S, Qin Y, Wang Z, Xiang J, Zhang Y, Xu $\mathrm{M}$, et al. Construction of a human monoclonal antibody against bFGF for suppression of NSCLC. J Cancer. 2018;9(11):2003-11.

80 Go RS, Lee SJ, Shin D, Callister SM, Jobe DA, Conry RM, et al. ECOG phase II trial of graded-dose peginterferon $a-2 b$ in patients with metastatic melanoma overexpressing basic fibroblast growth factor (E2602). Clin Cancer Res. 2013 Dec;19(23):6597-604.

81 Niehrs C. Function and biological roles of the Dickkopf family of Wnt modulators. Oncogene. 2006 Dec;25(57):7469-81.

82 Colozza G, Koo BK. Wnt $/ \beta$-catenin signaling: Structure, assembly and endocytosis of the signalosome. Dev Growth Differ. 2021 Apr; 63(3):199-218.

83 Deng F, Zhou R, Lin C, Yang S, Wang H, Li $\mathrm{W}$, et al. Tumor-secreted dickkopf2 accelerates aerobic glycolysis and promotes angiogenesis in colorectal cancer. Theranostics. 2019;9(4):1001-14.

84 Yamamoto S, Azuma E, Muramatsu M, Hamashima T, Ishii Y, Sasahara M. Significance of extracellular vesicles: pathobiologi$\mathrm{cal}$ roles in disease. Cell Struct Funct. 2016 Nov;41(2):137-43.

85 Andreu Z, Yáñez-Mó M. Tetraspanins in extracellular vesicle formation and function. Front Immunol. 2014;5:442.

86 Nazarenko I, Rana S, Baumann A, McAlear J Hellwig A, Trendelenburg M, et al. Cell surface tetraspanin Tspan8 contributes to molecular pathways of exosome-induced endothelial cell activation. Cancer Res. 2010 Feb; 70(4):1668-78

87 Ko SY, Lee W, Kenny HA, Dang LH, Ellis LM, Jonasch E, et al. Cancer-derived small extracellular vesicles promote angiogenesis by heparin-bound, bevacizumab-insensitive VEGF, independent of vesicle uptake. Commun Biol. 2019;2:386. 